\title{
Awareness Regarding Health Insurance Policy Scheme of Government of Nepal among Local Residents of Dharan Sub-Metropolitan City
}

\author{
- Roshni Thapa ${ }^{1} \cdot$ Shyam Lamsal ${ }^{2} \bullet$ Angur Badhu² $^{2}$ Sharmila Shrestha ${ }^{2}$
}

Submitted 2 March 2021

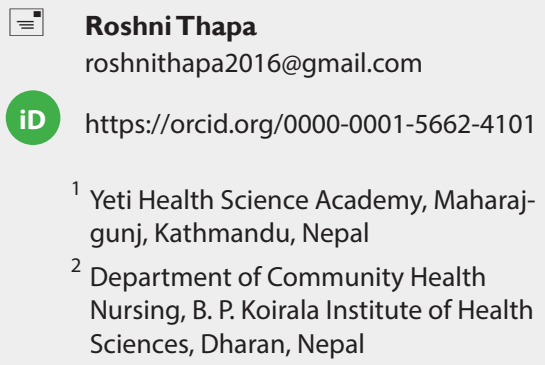

${ }^{1}$ Yeti Health Science Academy, Maharajgunj, Kathmandu, Nepal

2 Department of Community Health Nursing, B. P. Koirala Institute of Health Sciences, Dharan, Nepal

\section{Citation}

“Thapa R, Lamsal S, Badhu A, Shrestha S. Awareness regarding health insurance policy scheme of government of Nepal among local residents of Dharan sub-metropolitan city. JBPKIHS. 2021;4(1):32-36.

doi https://doi.org/10.3126/jbpkihs.v4i1.37764

\section{(c) (i) $\odot$}

This work is licensed under a Creative Commons AttributionNonCommercial 4.0 International License.
Accepted 4 May 2021

Published 30 June 2021

Background: An expensive care discourages people from using health services. The health insurance policy scheme of the government of Nepal aims to provide quality health care services without a financial burden to its citizens. We aimed to assess its awareness among local people of Dharan and also find its acceptance and association with various demographic variables.

Methods: This cross-sectional study was conducted among 249 households in 5 wards of Dharan sub-metropolitan city. Using a semi-structured questionnaire, a face-to-face interview was taken either from the financial decision maker/ financial supporter of the family. The socio-demographic characteristics, awareness and perception towards the health insurance policy scheme and its acceptance were assessed. The chi-square test was used to find the association of their awareness with different demographic variables.

Results: The majority $(70.7 \%)$ of the families were aware of the health insurance policy scheme. The most frequent source of knowledge was their friends/ family members (43.7\%) followed by insurance service providers (32.4\%). Only $36.6 \%$ of the families were enrolled in the health insurance policy scheme while $34.1 \%$ were not enrolled despite their knowledge about the scheme. Elderly (> 60 years), dependent, those without formal education, or those living below the poverty line were less aware regarding the health insurance policy $(p<0.05)$.

Conclusion: About $29 \%$ of families had no idea about health insurance policy scheme and $34.1 \%$ were not enrolled in it despite being aware of the scheme. Friends/ family members and insurance service providers were common sources of information.

Keywords: Awareness, Health insurance policy, Universal Health Coverage

\section{Declarations}

Ethics approval and consent to participate: Ethical approval obtained from the Institutional Review Committee, B. P. Koirala Institute of Health Sciences (Ref. No. -267/075/076-IRC). Informed written consent was taken from each participant before enrollment.

Consent for publication: Not applicable

Availability of data and materials: The datasets used and/ or analyzed during the current study are available from the corresponding author on reasonable request. All relevant data are within the manuscript.

Competing interest: None

Funding: None

Authors' contributions: RT: concept, design, data acquisition, and manuscript preparation. SL: design, manuscript preparation, data handling, manuscript review/ editing. AB: manuscript review/ editing. SS: tools, data acquisition, data analysis. All authors have read and approved the final manuscript.

Acknowledgement:We take this opportunity to extend our sincere thanks and indebtedness to all dignitaries and participants who helped us to complete this research study. This accomplishment would not have been possible without all of them. 
$\mathrm{T}$ he health services make a remarkable difference to individuals' health but direct payments/ privatization make health service expensive and unaffordable for many households, resulting in health problems in the community [1-3]. Every year, approximately 44 million households globally face catastrophic expenditure, and about 25 million families are pushed into poverty by the need to pay for services [4]. The impact is more severe on the poor and marginalized [5]. Although, Nepal's health financing and expenditure indicators were slightly better than those of the average low-income countries, out-of-pocket expenditure for health care accounted for more than 60\% [6]. In 2012, the government subsequently retracted user fees on primary health care services and implemented "health insurance policy scheme" which aimed to improve the access of health services to the poor and marginalized [7-9]. Although it covers the costs of medical treatment, medication and hospitalization of the insured in case of illness, accident and pregnancy, it has not yet been widely accepted by people [10]. Our primary objective was to assess the awareness regarding the health insurance policy scheme of the government of Nepal among local residents of Dharan. The secondary objective was to assess its acceptance and association with various demographic variables.

\section{METHODS}

$\mathrm{T}$ his cross-sectional study was conducted in 249 households of 5 wards (ward no 8, 11, 15, 17 and 18) from the total of 20 wards of Dharan sub-metropolitan city. Simple random sampling technique was used to select the wards (lottery method). The first house was selected randomly using random number generator, then all alternate households were taken.

Ethical clearance was obtained from the Institutional Review Committee of the university hospital of B. P. Koirala Institute of Health Sciences (BPKIHS), Dharan, Nepal. Permission was also obtained from the city office as well as the local administration office of the selected wards.

The financial decision maker/ financial supporter of the household who had lived in the city for at least 6 months was interviewed face to face. Informed written consent was taken from each participant before enrollment. Only one individual was interviewed from each household. To assess awareness and perception, a semi-structured questionnaire with a five-point Likertscale was developed based on literature review and ex- pert guidance. Awareness was defined as knowledge and consciousness about the health insurance policy scheme of the government of Nepal. The participants were categorized into various groups based on age, gender, marital status, ethnicity, education, occupation and economic status. Age was categorized into 20-40 years, 41-60 years, and > 60 years. Education was categorized into no formal education, primary level, secondary level and higher secondary or above. Occupation was classified as service holder, business, farmer, housewife, dependent, and labor. Dependent was defined as head of the family who took financial decision but was financially dependent on other family members. Socio-economic status of a household was assessed following the World Bank's new 2015 international poverty line measurement guideline as per capita income $<1.90$ USD/ day as under poverty line, and those with $>1.90$ as above poverty line [11].

Data was entered in the Microsoft Excel 2019 and analyzed using Statistical Package for Social Sciences version 11.5 (SPSS Inc; Chicago, IL, USA). Descriptive statistics like percentage, mean and standard deviation were used to describe demographic variables and awareness level. Inferential statistics such as the chisquare test was used to determine an association between awareness on health insurance policy scheme with the selected variables.

\section{RESULTS}

mong the total 249 households, the age of the respondents (mean $\pm \mathrm{SD}$ ) was $39.98 \pm 9.78$ years. The majority $(71.2 \%)$ were married and more than one third (73.2\%) belonged to the Janjati (Terai) ethnic group. More than one third (42.2\%) had no formal education, $73.8 \%$ were labors (skilled and unskilled) and $65.8 \%$ lived below the poverty line (Table 1). Seventy-three (29.3\%) respondents were unaware of the health insurance policy scheme (Fig. 1). Among the 176 respondents who had heard about it, the majority (77.3\%) knew that the health insurance scheme is a pure governmental institution, and $99.4 \%$ knew about the premium required. Only $36.6 \%$ families were enrolled in the health insurance policy scheme. The most common stated reason for non-enrollment despite knowledge of its existence was lack knowledge on how to enroll (Fig. 2). The most common source of information about health insurance scheme was friends/ family members (Fig. 3). Elderly ( $>60$ years), dependent, those without formal education, or those living below the pov- 


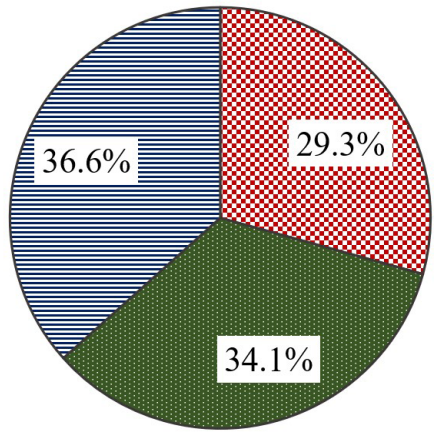

[ Unaware Aware but not enrolled 目 Aware and enrolled

Figure 1: Awareness and utilization of health insurance scheme $(n=249)$

erty line were less aware regarding the health insurance policy ( $<$ 0.05) (Table 1). The majority (67.1\%) strongly agreed on the importance of health insurance policy scheme and (69.3\%) perceived it as effective with wide coverage of services (Table 2). Almost 30.0\% of the respondents perceived that the insurance is difficult to obtain. Similarly, $59.1 \%$ of the respondents strongly agreed on the fact that the premium paid is affordable and $68.2 \%$

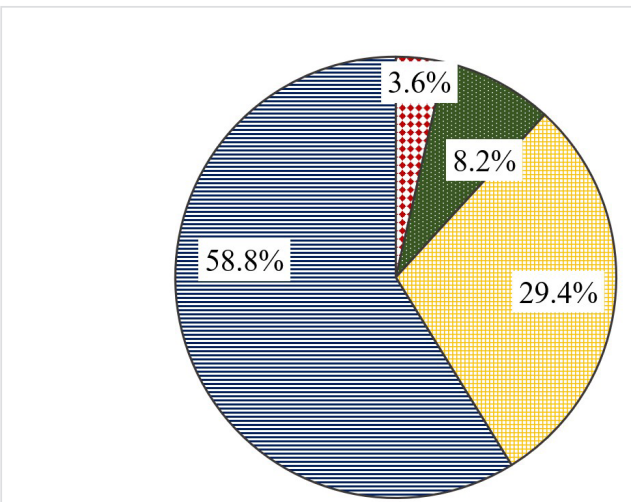

Too expensive Not necessary $\square$ Don't know how 目Others Figure 2: Reason for not enrolling $(n=85)$

perceived that the policy provided financial security.

\section{DISCUSSION}

This descriptive cross-sectional study was conducted to find out the awareness on the health insurance policy scheme of the government of Nepal among 249 households of Dharan. The authors believe that awareness re-

\begin{tabular}{|c|c|c|c|}
\hline Demographic variables & Awareness present & Awareness present $\mathrm{n}(\%)$ & $p$-value \\
\hline \multirow[t]{3}{*}{ Age $(y)$} & $21-40(n=109)$ & $89(81.6)$ & \multirow{3}{*}{0.001} \\
\hline & $4 I-60(n=102)$ & $70(68.6)$ & \\
\hline & $>60(n=38)$ & $17(44.7)$ & \\
\hline Gender & $M / F(1 / 2 / 137)$ & 78 (69.6)/ 98 (7I.5) & 0.74 \\
\hline Marital status & Unmarried/ Married (16/233) & $10(62.5) / 166(7 \mid .2)$ & 0.46 \\
\hline \multirow[t]{4}{*}{ Ethnicity } & Dalit $(n=25)$ & $14(56.0)$ & \multirow{4}{*}{0.34} \\
\hline & Janjati $(n=179)$ & $|3|(73.2)$ & \\
\hline & Madhesi $(n=3)$ & $2(66.6)$ & \\
\hline & Brahmin/ Chettri $(n=42)$ & $29(69.0)$ & \\
\hline \multirow[t]{4}{*}{ Education } & No formal $(n=90)$ & $38(42.2)$ & \multirow{4}{*}{$<0.001$} \\
\hline & Primary level $(n=15)$ & $15(100.0)$ & \\
\hline & Secondary level $(n=83)$ & 73 (87.9) & \\
\hline & Higher secondary and above $(n=61)$ & $50(81.9)$ & \\
\hline \multirow[t]{6}{*}{ Occupation } & Service $(n=35)$ & $31(88.6)$ & \multirow{6}{*}{$<0.001$} \\
\hline & Business $(n=57)$ & $46(80.7)$ & \\
\hline & Agriculture $(n=4)$ & $2(50.0)$ & \\
\hline & Housewife $(n=49)$ & $38(77.5)$ & \\
\hline & Dependent $(n=39)$ & II (28.2) & \\
\hline & Labor $(n=65)$ & $48(73.8)$ & \\
\hline $\begin{array}{l}\text { Economic status (with reference } \\
\text { to poverty line) }\end{array}$ & Below/ Above (I52/97) & $100(65.8) / 76(78.3)$ & 0.03 \\
\hline
\end{tabular}


Table 2: Perception of the residents towards health insurance policy scheme $(n=176)$. Values are presented as $n$ (\%).

\begin{tabular}{llllll}
\hline Parameters & \multicolumn{5}{c}{ Likert scale } \\
\cline { 2 - 6 } & 1 & 2 & 3 & 4 & 5 \\
\hline Importance and necessity of health insurance & $2(1.1)$ & $4(2.3)$ & $6(3.4)$ & $46(26.1)$ & $118(67.1)$ \\
Wide coverage of health insurance & $6(3.4)$ & $10(5.7)$ & $5(2.8)$ & $33(18.7)$ & $122(69.3)$ \\
Health insurance is difficult to obtain & $33(18.7)$ & $92(52.3)$ & $19(10.8)$ & $24(13.6)$ & $8(4.5)$ \\
Health insurance is affordable & $3(1.7)$ & $5(2.8)$ & $10(5.7)$ & $54(30.7)$ & $104(59.1)$ \\
Policy provides financial security & $3(1.7)$ & $3(1.7)$ & $12(6.8)$ & $38(21.6)$ & $120(68.2)$ \\
\hline
\end{tabular}

I: Strongly disagree, 2: Disagree, 3: Neutral, 4:Agree, 5: Strongly agree

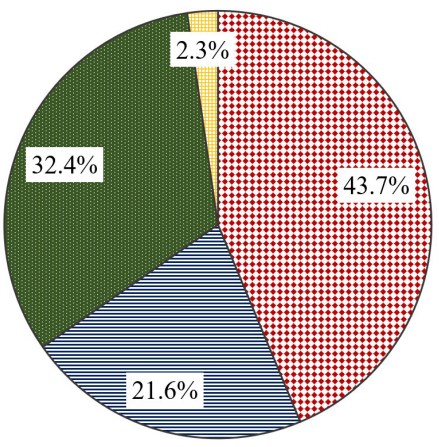

围Friends/ family members 目 TV/ newspaper/ radio $\square$ Insurance service provider $\square$ Others

Figure 3: Source of information $(n=176)$

garding health insurance policy scheme still needs to be improved as more than $29 \%$ of families had no idea about it. Similar result was seen in a study from 3 other districts (Baglung, Illam and Kailali) of Nepal [12]. Nevertheless, our figures are better than those reported in studies from different parts of India [13-15]. In a study from Andhra Pradesh, India, $66.5 \%$ people did not know about health insurance policy scheme of the government [16].

The sources of information about the health insurance policy scheme were mainly friends and family members followed by service providers. This reflects that Dharan is promoting health insurance policy scheme through the insurance service providers as well as through better communication within the community people. Similar findings are reported elsewhere [13, 14]. In contrast, a study from other districts of Nepal reported that the majority (74.0\%) knew about it from the radio [12].

In the present study, awareness increased with higher education and occupation such as business and services, which is similar to the finding of South India [13]. The lower socioeconomic group were less aware of the health insurance policy which is consistent with the study done in India $[15,17]$. This attributes to the fact that the higher socio-economic group was better off financially and also were more aware than the low socioeconomic group.

The statement that health insurance policy has wide risk coverage and could be a means of financial security was agreed by the majority of respondents. Other reports have stated that wide risk coverage was also the major factor for taking up health insurance policy scheme $[18,19]$. The majority $(67.1 \%)$ of our respondents strongly agreed that the health insurance policy scheme is necessary. Similarly, a study from Pokhara, Nepal found that $61.0 \%$ of the respondents had a positive perception on its necessity [19]. These findings are also consistent with the study conducted in Dhaka, Bangladesh [20].

We also found that only about $37 \%$ were enrolled in the health insurance policy scheme of the government of Nepal which is consistent with the result of a similar study in Punjab, India [17]. Despite awareness, the number of households utilizing the service was low since more than $34 \%$ of the families were aware of the scheme, yet not enrolled in it.

Since a very few studies have been conducted in relation to the health insurance policy scheme in $\mathrm{Ne}-$ pal, our findings may be useful for municipalities and government authorities. We recommend awareness campaigns to encourage the people to accept and utilize the health insurance policy scheme. The limitations of the study include a sample size from only 5 wards of a specific city. Hence, our findings cannot be generalized to other parts of the country.

\section{CONCLUSION}

bout $29 \%$ of families had no idea about health insurAance policy scheme and $34.1 \%$ were not enrolled in it despite being aware of the scheme. Friends/ family members and insurance service providers played an important role in dissemination of information. 


\section{References}

I. Shrestha MV, Manandhar N, Dhimal M, Joshi SK. Awareness on social health insurance scheme among locals in Bhaktapur Municipality. J Nepal Health Res Counc. 2020;18(3):422-5. DOI: 10.333|4/jnhrc.v18i3.247I.

2. Pekerti A, Vuong QH, Ho TM, Vuong TT. Health care payments in Vietnam: Patients' quagmire of caring for health versus economic destitution. Int J Environ Res Public Health. 2017; I4(I0): I I I8. DOI: $10.3390 /$ ijerph 14101 I I8.

3. Thuan N, Lofgren C, Chuck N, Janlert U, Lindholm L. Household out-of-pocket payments for illness: Evidence from Vietnam. BMC Public Health. 2006;6:283. DOI: I 0. I 186/ I 47|-2458-6-283.9

4. World Health Organization. Country cooperation strategy at a glance: Federal Democratic Republic of Nepal. 2014;(April 20I4):2012-3. Available from: http://www.searo.who.int/nepal/ ccs_countryprofile.pdf

5. Pant C. Health Insurance: New beginning to health care in Nepal. Journal of Lumbini Medical College. 20 I7;5(I):I-2. DOI: 10.22502/ jlmc.v5il. 127

6. World Health Organization. Chapter 2: How well do health systems perform? In:The World Health Report 2000 Health systems: Improving performance. Geneva:WHO; 2000. p. 21 -46.

7. Stoermer M, Fuerst F, Rijal K, Bhandari R, Nogier C, Gautam GS, et al. Review of community-based health insurance initiatives in Nepal. GIZ. 2012.

8. Mishra SR, Khana IP, Karki DK, Kallestrup P, Enemark U. National health insurance policy in Nepal: challenges for implementation. Glob Health Action. 2015;8:28763. DOI: 10.3402/gha.v8.28763

9. Lohani GR. Social health security program. Social Health Security Development Committee. 2019.

10. Ranabhat CL, Kim CB, Singh DR, Park MB. A comparative study on outcome of government and co-operative community-based health insurance in Nepal. Front Public Health. 2017;5:250. DOI: 10.3389/fpubh.2017.00250

II. The World Bank. FAQs: Global Poverty Line Update. 2015 September 30. Available from:https://www.worldbank.org/en/topic/ poverty/brief/global-poverty-line-faq

12. NHRC. Assessment of social health insurance scheme in selected districts of Nepal. Kathmandu, Nepal. Nepal Health Research
Council; 2018.

13. Reshmi B, Shreekumaran NN, Sabu KM, Unnikrishnan B. Awareness of health insurance in a south Indian population - a community-based study. Health Population; Perspective and Issues.2007;30(3): 177-88. DOI: 10.4103/0970-0218.69288

14. Choudhary ML, Goswami KI, Khambhati SB, Shah VR, Makwana NR, Yadav SB. Awareness of health insurance and related issues in rural areas of Jamnagar district. National Journal of Community Medicine. 20I 2;4(2):267-7I.

I5. Madhu KS, Sudeepa D, Gaikwad V. Awareness and perception regarding health insurance in Bangalore rural population. International Journal of Medicine Public Health 20I2;2(2):18-22. DOI: I0.5530/ijmedph.2.2.5

16. Yellaiah Scholar J. Awareness of health insurance in Andhra Pradesh. International Journal of Scientific and Research Publications. 20| 2;2(6): I-6.

17. Bawa SK,Verma R.Awareness and willingness to pay for health insurance: An empirical study with reference to Punjab India. International Journal of Humanities and Social Science. 20I I; I (7): I008.

18. Panchal N. Customer's perception towards health insurance: An empirical study in Bardoli \& Mandvi Region. Indian Journal of Applied Research. 2014;3(4):62-4. DOI: 10.15373/2249555X\%2FAPR2013\%2F84

19. Gurung JB. Insureds' perception towards insurance services in Pokhara. Repositioning Journal of Bus Hosp. 2016; /:23-36.DOI: 10.3126/repos.vli0.16040

20. Hamid SA, Baki Billah AH. The Perception and attitude towards health insurance among the students of Dhaka University. SSRN Electronic Journal. 2016. DOI: I0.2139/ssrn.3092458 